\title{
PENGARUH STRES KERJA DAN KONDISI FISIK KERJA TERHADAP KINERJA DOSEN DAN TENAGA KEPENDIDIKAN PADA SEKOLAH TINGGI ILMU EKONOMI AMA SALATIGA
}

\author{
Oleh : \\ Edi Murgijanto \\ STIE AMA Salatiga
}

\begin{abstract}
Abstrak
Human resources as organizational assets are very decisive in the success of organizations including the STIE AMA Salatiga. The participation of the lecturers and education staff cannot be released in order to achieve the stated goals. Lecturers and education staff who are working require adequate physical work conditions and not high levels of stress to be able to perform better. The study was conducted to determine the effect of work stress and physical work conditions on the performance of lecturers and education staff at the AMA Salatiga College of Economics. The results of the study are expected to be an input for STIE AMA Salatiga in taking policies in an effort to improve the performance of lecturers and education staff, and are expected to have an impact on achieving the Function, Vision, Mission and Objectives of STIE AMA Salatiga. Based on the results of data analysis, researchers can draw conclusions about the effect of work stress and physical work conditions on the performance of lecturers and education staff at STIE AMA Salatiga as follows: The results of the validity test and reliability test show that each item statement and each research variable are declared valid and reliable. While the results of the partial test of work stress variables do not have a significant effect on the performance variables, while the physical condition variables work significantly influence the performance variables. Then simultaneous testing of work stress variables and physical conditions of work has a significant effect on performance variables. The coefficient of determination ( $R$ Square) is 0.20, this means that the independent variables of work stress and physical conditions of work can explain the dependent variable of performance by $20 \%$ and the remaining $80 \%$ explained by other factors not examined.
\end{abstract}

Keywords : Stres Kerja, Kondisi Fisik Kerja, Kinerja.

\section{PENDAHULUAN}

Sumber daya manusia sebagai aset organisasi sangat menentukan dalam keberhasilan organisasi termasuk lembaga pendidikan tinggi. Lembaga pendidikan tinggi dalam hal ini perguruan tinggi didirikan dengan tujuan untuk memberikan pelayanan dibidang pendidikan tinggi kepada masyarakat secara optimal.

Pengaruh Stres Kerja Dan Kondisi Fisik Kerja Terhadap Kinerja Dosen Dan Tenaga Kependidikan 
Dalam rangka perguruan tinggi mencapai tujuan yang telah ditetapkan, maka peran serta dari para dosen dan tenaga kependidikannya tidak dapat dilepaskan. Dosen mempunyai peran yang sangat penting dalam mencapai tujuan tersebut. Hal ini dapat dilihat dari segala aktivitas yang dilakukan oleh para dosen yang meliputi bidang pendidikan dan pengajaran, penelitian serta pengabdian kepada masyarakat yang dikenal dengan Tridarma Perguruan Tinggi. Demikian juga peran yang dilaksanakan para tenaga kependidikan dalam mendukung tercapainya tujuan tersebut.

Untuk menunjang keberhasilan tujuan suatu perguruan tinggi diperlukan adanya sumber daya manusia dosen dan tenaga kependidikan yang berkinerja baik. Agar para dosen dan tenaga kependidikan dapat berkinerja baik antara lain dibutuhkan tingkat stres yang tidak tinggi dan kondisi fisik kerja yang memadai.

Menurut Wilson Bangun (2012), kinerja merupakan variabel tidak bebas (dependent variable) yang dipengaruhi oleh banyak faktor yang mempunyai arti dalam penyampaian tujuan organisasional. Artinya, kesalahan dalam pengelolaan pada variabel bebas (dependent variable) akan berakibat pada kinerja, baik secara negatif maupun positif.

A.A. Anwar Prabu Mangkunegara (2011) memberikan pengertian kinerja (prestasi kerja) yaitu hasil kerja secara kualitas dan kuantitas yang dicapai seseorang karyawan dalam melaksanakan tugasnya sesuai dengan tanggung jawab yang diberikan kepadanya.

Dalam bekerja berbagai bentuk kekuatiran dan masalah selalu dihadapi. Dari waktu ke waktu menjumpai kesulitan-kesulitan, masalah-masalah dan mengalami kesedihan emosional baik di dalam maupun di luar pekerjaan dan hal ini bisa mempenguruhi kinerja seseorang (Handoko, 2011). Ini yang dapat menyebabkan seseorang mengalami stres.

Menurut A.A. Anwar Prabu Mangkunegara (2011), Stres kerja adalah perasaan tertekan yang dialami karyawan dalam menghadapi pekerjaan. 
Stres yang terlalu besar dapat mengancam kemampuan seseorang untuk menghadapi lingkungan, yang selanjutnya dapat mengganggu pelaksanaan tugas-tugasnya, yang berarti akan mengganggu kinerja mereka (Handoko, 2011).

Disamping masalah stres kerja yang dihadapi seseorang dalam bekerja juga salah satunya adalah masalah kondisi fisik kerja.

Menurut A.A. Anwar Prabu Mangkunegara (2005), kondisi fisik kerja adalah faktor yang mencakup penerangan (cahaya), suara, warna, musik, temperatur dan kelembapan.

Dijelaskan selanjutnya oleh A.A. Anwar Prabu Mangkunegara (2005), bahwa kondisi kerja adalah semua aspek kondisi fisik kerja, kondisi psikologis kerja dan peraturan kerja yang dapat mempengaruhi kepuasan kerja dan pencapaian produktivitas kerja.

Bila stres kerja terjadi terlalu besar dan kondisi fisik kerja kurang memadai, maka berakibat kinerja dosen dan tenaga kependidikan akan menurun dan tentu selanjutnya akan memengaruhi pencapian tujuan organisasi.

Sekolah Tinggi Ilmu Ekonomi AMA Salatiga merupakan organisasi yang bergerak dibidang pendidikan. Dalam organisasi seperti ini, dosen dan tenaga kependidikan merupakan faktor masukan yang melakukan proses untuk menciptakan keluaran yang baik. Manajemen STIE AMA mempunyai tujuan yang harus dicapai melalui dosen dan tenaga kependidikan yang ada sebagai pelaku dalam proses pencapaian tujuan tersebut. Oleh karena itu diperlukan pengelolaan yang baik terkait stres kerja dan kondisi fisik kerja agar para dosen dan tenaga kependidikan dapat berkinerja yang lebih baik. Sementara pada saat ini sedang ada renovasi kampus secara besar-besaran yang dilakukan pihak Yayasan, sudah barang tentu ada dampaknya terhadap para dosen dan tenaga kependidikan dalam menjalankan aktivitasnya.

Berdasarkan uraian latar belakang diatas maka rumusan permasalahan penelitian ini adalah : Adakah pengaruh stres kerja dan kondisi fisik kerja terhadap kinerja dosen dan tenaga kependidikan pada Sekolah Tinggi Ilmu Ekonomi AMA Salatiga ?. Tujuan Penelitian ini adalah untuk mengetahui pengaruh stres kerja dan kondisi fisik kerja baik

Pengaruh Stres Kerja Dan Kondisi Fisik Kerja Terhadap Kinerja Dosen Dan Tenaga Kependidikan Pada Sekolah Tinggi Ilmu Ekonomi AMA Salatiga (Edi Murgijanto) 
secara sendiri-sendiri maupun secara simultan terhadap kinerja dosen dan tenaga kependidikan pada Sekolah Tinggi Ilmu Ekonomi AMA Salatiga.

\section{TINJAUAN PUSTAKA}

\section{Stres Kerja}

Menurut Tim Mitra Bestari (2005), Stres kerja merupakan istilah umum yang menunjuk pada tekanan dan masalah yang dialami oleh setiap orang dalam kehidupannya sehari-hari.

Jika orang dapat mengatur atau mengelola stres dengan baik maka secara psikologis akan menumbuhkan semangat dan motivasi dalam bekerja. Sebaliknya jika stres terlalu berlebihan akan menyebabkan terganggunya kesehatan baik fisik maupun non fisik (Tim Mitra Bestari, 2005).

Selanjutnya Anwar Prabu Mangkunegara (2004), mengemukakan stres kerja nampak dari perilaku dengan symptom (gejala) seperti emosi tidak stabil, agresif, mudah marah, sikap tidak kooperatip, perasaan tidak tenang, suka menyendiri, sulit tidur, merokok berlebihan, tidak bisa rileks, cemas, tegang, gugup, tekanan darah meningkat, dan mengalami gangguan pencernaan.

Banyak kondisi yang bisa menyebabkan seseorang mengalami stres. Meskipun demikian hanya dengan satu penyebab saja, seseorang bisa mengalami stres. Pada umumnya karyawan mengalami stres karena lebih dari satu penyebab stres.

Menurut A.A. Anwar Prabu Mangkunegara (2011), Stres kerja adalah perasaan tertekan yang dialami karyawan dalam menghadapi pekerjaan.

Berikut adalah kondisi-kondisi yang bisa menyebabkan seseorang mengalami stres.

A.A. Anwar Prabu Mangkunegara (2011), mengemukakan beberapa faktor yang menjadi penyebab stress kerja yaitu:

a. Beban kerja yang terlalu berat

b. Waktu kerja yang mendesak

c. Kualitas pengawasan yang rendah 
d. Iklim kerja yang tidak sehat

e. Wewenang yang tidak mencukupi untuk melaksanakan tanggung jawab

f. Konflik kerja

g. Perbedaan nilai-nilai antara pimpinandengan karyawan

\section{Kondisi Fisik Kerja}

Kondisi fisik kerja merupakan faktor yang mencakup penerangan (cahaya), suara, warna, musik, temperatur dan kelembapan (A.A. Anwar Prabu Mangkunegara, 2005).

1. Penerangan (Cahaya)

Cahaya lampu yang tidak memadai berpengaruh negatif terhadap ketrampilan kerja.

Penerangan dan cahaya lampu harus pula disesuaikan dengan luas ukuran ruangan kerja serta kondisi mata karyawan, khususnya karyawan yang matanya plus dan minus yang akut.

\section{Kondisi Suara}

Kondisi suara adalah suara di dalam kantor maupun di luar kantor. Suara yang dirasakan gaduh oleh karyawan akan berpengaruh terhadap konsentrasi kerja.

3. Warna

Warna ruang kantor yang serasi dapat meningkatkan produksi, meningkatkan moral kerja, menurunkan kecelakaan, dan menurunkan terjadinya kesalahan kerja.

Penentuan warna dalam ruang kerja sangat mempengaruhi perilaku kerja. Oleh karena itu, pemilihan warna perlu disesuaikan dengan luas ukuran ruangan dan kondisi fisik ruang.

4. Musik

Penggunaan musik pada jam kerja ternyata berpengaruh positif terhadap semangat kerja dan meningkatkan produksi. Bahkan penggunaan musik pun dapat menurunkan tingkat absensi dan mengurangi kelelahan dalam bekerja.

Oleh karena itu, penggunaan musik kerja perlu disesuaikan dengan kesukaan karyawan dan kondisi ruang kerja.

5. Temperatur dan Kelembapan

Pengaruh Stres Kerja Dan Kondisi Fisik Kerja Terhadap Kinerja Dosen Dan Tenaga Kependidikan Pada Sekolah Tinggi Ilmu Ekonomi AMA Salatiga (Edi Murgijanto) 
Temperatur dan kelembapan dapat mempengaruhi semangat kerja, kondisi fisik, dan emosi. Temperatur yang terlalu panas atau terlalu dingin dapat mempengaruhi kondisi fisik dan emosi karyawan.

\section{Kinerja}

Menurut Malayu SP Hasibuan (2005), prestasi kerja/kinerja adalah suatu hasil kerja yang dicapai seseorang dalam melaksanakan tugas-tugas yang dibebankan kepadanya yang didasarkan kecakapan, pengalaman dan kesungguhan serta waktu.

Kemudian menurut A.A. Anwar Prabu Mangkunegara (2011), kinerja karyawan adalah hasil kerja secara kualitas dan kuantitas yang dicapai oleh seorang pegawai dalam melaksanakan tugasnya sesuai dengan tanggung jawab yang diberikan kepadanya.

Kinerja juga dapat diartikan melakukan suatu kegiatan dan menyempurnakannya sesuai dengan tanggung jawabnya dengan hasil sesuai yang diharapkan. Hal ini menunjukkan bahwa kinerja karyawan itu ditentukan oleh kemampuan dan ketrampilan yang dimiliki mereka dalam mencapai tujuan bersama.

Menurut A.A. Anwar Prabu Mangkunegara (2011), unsur-unsur kinerja sebagai berikut :

a. Kualitas Kerja berkaitan dengan ketepatan, ketelitian, keterampilan dan kebersihan.

b. Kuantitas Kerja berkaitan dengan output dan seberapa cepat dapat menyelesaikan kerja extra.

c. Keandalan dalam mengikuti intruksi, berinisiatif, kehati-hatian serta kerajinan d. Sikap adalah sikap terhadap organisasi, pegawai lain, pekerjaan dan kerjasama.

\section{Hipotesis}

Berdasarkan pada perumusan masalah dan landasan teori di atas maka penulis membuat hipotesis sebagai berikut: Ada pengaruh yang signifikan stres kerja dan kondisi fisik kerja baik secara parsial maupun secara simultan terhadap kinerja dosen dan tenaga kependidikan pada Sekolah Tinggi Ilmu Ekonomi AMA Salatiga. 


\section{METODE PENELITIAN}

\section{Tipe Penelitian}

Dalam penelitian ini tipe penelitiannya termasuk tipe penelitian Eksplanatori. Penelitian eksplanatori adalah penelitian yang berusaha untuk menguji hipotesis yang menyatakan hubungan sebab akibat antara dua variabel atau lebih (Sukandarrumidi, 2006).

\section{Populasi dan Sampel}

Dalam penelitian ini yang menjadi populasi adalah adalah dosen dan tenaga kependidikan Sekolah Tinggi Ilmu Ekonomi AMA Salatiga.Untuk dosen kriteria sampel yang diambil adalah dosen yang sudah mengajar minimal 2 tahun dan minimal 2 klas/mata kuliah. Dengan demikian pengambilan sampel menggunakan teknik purposive sampling yaitu teknik pengambilan sampel berdasarkan kriteria tertentu.

\section{Definisi Operasional}

Definisi operasional dalam penelitian ini adalah sebagai berikut:

Stres Kerja (X1) dalam penelitian ini diukur dengan indikator-indikator yaitu : beban kerja yang terlalu berat, waktu kerja yang mendesak, kualitas pengawasan yang rendah, iklim kerja yang tidak sehat, wewenang yang tidak mencukupi untuk melaksanakan tanggung jawab, konflik kerja dan perbedaan nilai-nilai antara pimpinan dengan karyawan.

Kondisi Fisik Kerja (X2) dalam penelitian ini diukur dengan indikator-indikator yaitu : penerangan (cahaya), kondisi suara, warna serta temperatur dan kelembapan.

Kinerja (Y) dalam penelitian ini diukur dengan indikator-indikator yaitu: kualitas, kuantitas, keandalan dan sikap.

Dalam penelitian ini, skala Likert digunakan untuk mengukur sikap, pendapat dan persepsi responden atas pertanyaan yang diajukan sebagai berikut :

Sangat Setuju (SS) diberi skor 5, Setuju (S) diberi skor 4, Ragu-Ragu (RR) diberi skor 3, Tidak Setuju (TS) diberi skor 2, Sangat Tidak Setuju (STS) diberi skor 1.

\section{Metode Analisis Data}

Pengaruh Stres Kerja Dan Kondisi Fisik Kerja Terhadap Kinerja Dosen Dan Tenaga Kependidikan 
Analisis data penelitian ini menggunakan beberapa teknik analisis sebagai berikut:

\section{Uji Validitas}

Uji validitas adalah untuk mengukur tingkat kesahihan suatu instrumen tentang apa yang seharusnya diukur. Untuk mengukur validitas digunakan rumus korelasi product moment Pearson, bila :

$\mathrm{r}$ hitung > $\mathrm{r}$ tabel, berarti pengujian validitas dikatakan valid.

$r$ hitung < $r$ tabel, berarti pengujian validitas dikatakan tidak valid.

\section{Uji Reliabilitas}

Pengukuran yang memiliki reliabilitas tinggi disebut sebagai pengukuran yang reliabel. Suatu alat ukur dikatakan reliabel jika koefisien Alpha/Cronbach Alpha > 0,60 (Nunnally, dalam Imam Gozali, 2001).

\section{Analisis Regresi Linear Berganda}

Analisis dilakukan dengan rumus regresi linear berganda sebagai berikut:

$\mathrm{Y}=\mathrm{a}+\mathrm{b} 1 \mathrm{X} 1+\mathrm{b} 2 \mathrm{X} 2$.

Dimana : Y adalah variabel kinerja, a adalah bilangan konstan, b1 dan b2 adalah koefisien regresi, X1 adalah variabel stres kerja dan X2 adalah variabel kondisi fisik kerja.

\section{Uji t}

Uji t dilakukan untuk mengetahui pengaruh yang signifikan stres kerja (X1) dan kondisi fisik kerja (X2) secara partial terhadap kinerja (Y).

Ho: $\beta 1, \beta 2=0$, berarti tidak ada pengaruh yang signifikan antara (X1) dan (X2) secara partial, terhadap $(\mathrm{Y})$.

Ha: $\beta 1, \beta 2 \neq 0$, berarti ada pengaruh yang signifikan antara (X1) dan (X2) secara partial, terhadap Y

\section{Uji F}

Uji F dilakukan untuk mengetahui pengaruh yang signifikan stres kerja (X1) dan kondisi fisik kerja (X2) secara simultan terhadap kinerja (Y).

Ho: $\beta 1, \beta 2=0$, berarti tidak ada pengaruh yang signifikan antara (X1) dan (X2) secara simultan, terhadap (Y). 
Ha: $\beta 1, \beta 2>0$, berarti ada pengaruh yang signifikan antara $(\mathrm{X} 1)$ dan $(\mathrm{X} 2)$ secara simultan, terhadap $\mathrm{Y}$

\section{Koefisien Determinasi ( $R$ Square)}

Koefisien determinasi digunakan untuk mengetahui besarnya sumbangan variabel independen stres kerja (X1) dan kondisi fisik kerja (X2) terhadap variabel dependen kinerja (Y) yang ditunjukkan oleh nilai R Square.

\section{HASIL DAN PEMBAHASAN}

Penelitian ini sebagai responden adalah dosen dan tenaga kependidikan Sekolah Tinggi Ilmu Ekonomi AMA Salatiga yang berjumlah 34 orang dosen dan tenaga kependidikan.

Dari hasil analisis data penelitian dapat diuraikan penjelasan sebagai berikut :

\section{Hasil Uji Validitas Kuesioner Penelitian}

Dari hasil analisis uji validitas didapati bahwa nilai $r$ hitung masing-masing butir pertanyaan dari 0,382 sampai 0,841 > r tabel 0,339. Oleh karena itu kuesioner penelitian dikatakan valid.

\section{Hasil Uji Reliabilitas Kuesioner Penelitian}

Berdasarkan hasil uji dengan SPSS diperoleh hasil bahwa nilai cronbach alpha variabel stres kerja 0,778, kondisi fisik kerja 0,780 dan kinerja 0,767>0,6 sehingga indikator pada masing-masing variabel penelitian dapat dikatakan reliabel.

\section{Analisis Regresi Linier Berganda}

Dari hasil analisis regresi linier berganda pengaruh antara stres kerjadan kondisi fisik kerja yang merupakan variabel independen terhadap kinerja yang merupakan variabel dependen diuraikan pada tabel di bawah ini :

\section{Tabel 1}

\section{Hasil Perhitungan Regresi Linier Berganda}

Coefficients $^{a}$

\begin{tabular}{|c|c|c|c|c|c|}
\hline \multirow[t]{2}{*}{ Model } & \multicolumn{2}{|c|}{ Unstandardized Coefficients } & \multirow{2}{*}{$\begin{array}{c}\text { Standardized } \\
\text { Coefficients } \\
\text { Beta }\end{array}$} & \multirow[b]{2}{*}{$t$} & \multirow[b]{2}{*}{ Sig. } \\
\hline & $\mathrm{B}$ & Std. Error & & & \\
\hline 1 (Constant) & 28.601 & 3.767 & & 7.593 & .000 \\
\hline _ STRES KERJA (X1) & -.098 & .094 & -.176 & -1.040 & .306 \\
\hline
\end{tabular}

Pengaruh Stres Kerja Dan Kondisi Fisik Kerja Terhadap Kinerja Dosen Dan Tenaga Kependidikan Pada Sekolah Tinggi Ilmu Ekonomi AMA Salatiga (Edi Murgijanto) 


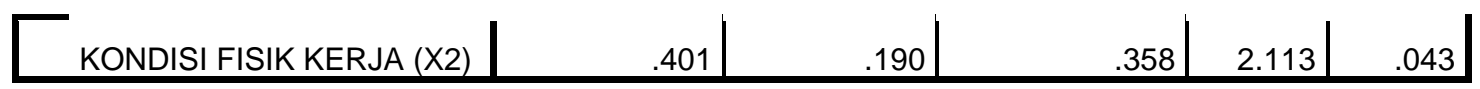

a. Dependent Variable: KINERJA (Y)

Sumber : Data Primer Yang Diolah, 2018

Dari model regresi di atas diperoleh persamaan garis regresi $\mathrm{Y}=28,601-0,098 \mathrm{X} 1$ $+0,401 \mathrm{X} 2$.

\section{Uji Hipotesis Penelitian}

\section{Pengujian Hipotesis I Penelitian}

Dari hasil analisis data diperoleh nilai t-hitung sebagai berikut:

Pengujian hipotesis I dilakukan dengan uji t. Pengujian ini bertujuan untuk mengetahui pengaruh stres kerja terhadap kinerja dosen dan tenaga kependidikan pada Sekolah Tinggi Ilmu Ekonomi AMA Salatiga.

Dengan menggunakan tingkat signifikansi $0,025(\alpha=0,05 / 2)$, dan degree of freedom $(n-k-1)=31$ dari hasil perhitungan diperoleh $t_{\text {tabel }}$ sebesar 2,04. Dari perhitungan dengan program SPSS dihasilkan $t_{\text {hitung }}$ sebesar -1,040 menunjukkan bahwa - $t_{\text {hitung }}$ lebih besar daripada $-t_{\text {tabel }}(-1,040>-2,04)$ sehingga keputusannya adalah menerima $\mathrm{H}_{\mathrm{o}}$ dan menolak $\mathrm{H}_{\mathrm{a}}$.

Dengan demikian pernyataan hipotesis I penelitian "Terdapat pengaruh signifikan stres kerja terhadap kinerja dosen dan tenaga kependidikan pada Sekolah Tinggi Ilmu Ekonomi AMA Salatiga" tidak dapat diterima atau ditolak.

\section{Pengujian Hipotesis II Penelitian}

Pengujian hipotesis II penelitian dilakukan dengan uji t. Pengujian hipotesis II penelitian ini bertujuan untuk mengetahui pengaruh kondisi fisik kerjaterhadap kinerja dosen dan tenaga kependidikan pada Sekolah Tinggi Ilmu Ekonomi AMA Salatiga.

Dengan menggunakan taraf signifikansi $0,025(\alpha=0,05 / 2)$, dan degree of freedom $(\mathrm{n}-\mathrm{k}-1)=31$ dari hasil perhitungan diperoleh nilai tabel sebesar 2,04. Dari perhitungan dengan program SPSS dihasilkan thitung sebesar 2,113 menunjukkan bahwa $t_{\text {hitung }}$ lebih besar daripada $t_{\text {tabel }}(2,113>2,04)$ sehingga keputusannya adalah menerima $\mathrm{H}_{\mathrm{a}}$ dan menolak $\mathrm{H}_{\mathrm{o}}$. Dengan demikian pernyataan hipotesis II penelitian yang menyatakan 
"Terdapat pengaruh signifikan kondisi fisik kerja terhadap kinerja dosen dan tenaga kependidikan pada Sekolah Tinggi Ilmu Ekonomi AMA Salatiga” dapat diterima.

\section{Pengujian Hipotesis III Penelitian}

Adapun pernyataan hipotesis III penelitian adalah "Terdapat pengaruh signifikan stres kerja dan kondisi fisik kerja secara simultan terhadap kinerjadosen dan tenaga kependidikan pada Sekolah Tinggi Ilmu Ekonomi AMA Salatiga”.

Hasil uji F dengan menggunakan alat analisis regresi linier berganda dapat dilihat pada tabel di bawah ini:

Tabel 2

Nilai F-hitung

ANOVA

\begin{tabular}{|l|r|r|r|l|l|}
\hline Model & Sum of Squares & Df & Square & F & Sig. \\
\hline Regression & 61.225 & 2 & 30.612 & 3.879 & $.031^{\mathrm{a}}$ \\
Residual & 244.658 & 31 & 7.892 & & \\
Total & 305.882 & 33 & & & \\
\hline
\end{tabular}

a. Predictors: (Constant), KONDISI FISIK KERJA (X2), STRES KERJA (X1)

b. Dependent Variable: KINERJA (Y)

Sumber : Data Primer Yang Diolah, 2018

Berdasarkan tabel tersebut di atas dapat diuraikan bahwa nilai F-hitung hasil analisis regresi adalah sebesar 3.879. Kemudian dengan menggunakan signifikansi 5\% ( $\alpha$ $=0.05)$ dan degree of freedom $2(\mathrm{k})$ dan $31(\mathrm{n}-\mathrm{k}-1)$, dihasilkan nilai $\mathrm{F}_{\text {tabel }}$ sebesar 3,30. Menunjukkan bahwa nilai $F_{\text {hitung }}$ lebih besar daripada $F_{\text {tabel }}(3,879>3,30)$. Hal ini berarti bahwa secara simultan variabel-variabel independen mempunyai pengaruh yang signifikan terhadap variabel dependen. Dengan demikian Hipotesis III penelitian yang menyatakan "Terdapat pengaruh signifikan stres kerja dan kondisi fisik kerja secara simultan terhadap kinerja dosen dan tenaga kependidikan pada Sekolah Tinggi Ilmu Ekonomi AMA Salatiga” dapat diterima.

\section{Koefisien Determinasi $(R$ Square $)$}


Koefisien determinasi digunakan untuk melihat berapa persen (\%) dari variabel dependen $(\mathrm{Y}=$ kinerja) dapat diterangkan oleh variasi dari variabel independen yang terdiri dari stres kerja $\left(\mathrm{X}_{1}\right)$ dan kondisi fisik kerja $\left(\mathrm{X}_{2}\right)$.

Dari hasil analisis data dengan menggunakan program SPSS diperoleh nilai koefisien determinasi ( $R$ Square) sebagai berikut:

Tabel 3

Koefisien Determinasi (R Square)

\begin{tabular}{|l|r|r|r|c|}
\multicolumn{7}{|c|}{ Model Summary } \\
\hline Model & $\mathrm{R}$ & $\mathrm{R}$ Square & $\begin{array}{c}\text { Adjusted R } \\
\text { Square }\end{array}$ & $\begin{array}{c}\text { Std. Error of the } \\
\text { Estimate }\end{array}$ \\
\hline 1 & $.447^{\mathrm{a}}$ & .200 & .149 & 2.80930 \\
\hline
\end{tabular}

a. Predictors: (Constant), KONDISI FISIK KERJA (X2), STRES KERJA (X1)

Sumber : Data Primer Yang Diolah, 2018

Dari tabel tersebut di atas dapat dilihat bahwa besarnya nilai koefisien determinasi (R. Square) dari hasil perhitungan adalah sebesar 0,20 atau 20\%. Hal ini berarti variasi variabel stres kerja dan kondisi fisik kerja dapat menjelaskan variabel kinerja dosen dan tenaga kependidikan sebesar $20 \%$ dan sisanya $80 \%$ dijelaskan oleh variabel lain yang tidak diteliti.

\section{SIMPULAN}

Berdasarkan hasil analisis data dan pembahasan dapat disimpulkan sebagai berikut :

1. Persamaan regresi linier berganda dalam penelitian ini adalah $\mathrm{Y}=28,601-0,098 \mathrm{X} 1$ $+0,401 \times 2$.

2. Hipotesis I penelitian "Terdapat pengaruh signifikan stres kerja terhadap kinerja dosen dan tenaga kependidikan pada Sekolah Tinggi Ilmu Ekonomi AMA Salatiga" tidak dapat diterima atau ditolak dibuktikan dengan nilai $-\mathrm{t}_{\text {hitung }}$ lebih besar daripada $-t_{\text {tabel }}(-1,040>-2,04)$. 
3. Hipotesis II penelitian yang menyatakan "Terdapat pengaruh signifikan kondisi fisik kerja terhadap kinerja dosen dan tenaga kependidikan pada Sekolah Tinggi Ilmu Ekonomi AMA Salatiga" dapat diterima dibuktikan dengan nilai thitung lebih besar daripada tabel $(2,113>2,04)$.

4. Hipotesis III penelitian "Terdapat pengaruh signifikan stres kerja dan kondisi fisik kerja secara simultan terhadap kinerja dosen dan tenaga kependidikan pada Sekolah Tinggi Ilmu Ekonomi AMA Salatiga" dapat diterima dibuktikan dengan nilai nilai $\mathrm{F}_{\text {hitung }}$ lebih besar daripada $\mathrm{F}_{\text {tabel }}(3,879>3,30)$.

5. Nilai koefisien determinasi (R. Square) dari hasil perhitungan adalah sebesar 0,20. Hal ini berarti variasi variabel stres kerja dan kondisi fisik kerja dapat menjelaskan variabel kinerja dosen dan tenaga kependidikan sebesar 20\% dan sisanya $80 \%$ dijelaskan oleh variabel lain yang tidak diteliti.

\section{SARAN}

Berdasarkan hasil penelitian dapat dilihat bahwa kontribusi variabel kondisi fisik kerja mempunyai pengaruh yang signifikan terhadap peningkatan kinerja dosen dan tenaga kependidikan dibandingkan stres kerja. Hal ini menunjukkan bahwa kinerja dosen dan tenaga kependidikan STIE AMA Salatiga lebih dipengaruhi oleh faktor kondisi fisik kerja, untuk itu saran yang dapat diberikan oleh peneliti sehubungan dengan hasil penelitian tersebut adalah: ada baiknya apabila pihak STIE AMA Salatiga dan Yayasan berusaha meningkatkan kondisi fisik kerja seperti meningkatkan penerangan dan cahaya lampu ruangan kerja, kemudian suara di lingkungan kerja yang dapat berpengaruh terhadap konsentrasi dapat dikurangi lagi, pewarnaan ruang kerja lebih diperhatikan serta temperatur ruang kerja untuk melaksanakan pekerjaan dalam kondisi yang memadai tanpa melupakan penurunan faktor stres kerja guna meningkatkan kinerja dosen dan tenaga kependidikan Sekolah Tinggi Ilmu Ekonomi AMA Salatiga.

\section{DAFTAR PUSTAKA}

Arikunto, Suharsimi. 2002. Prosedur Penelitian Suatu Pendekatan Praktek. Rineka Cipta, Jakarta. 
Azwar, Saifuddin, 2005. Metode Penelitian. Pustaka Pelajar, Yogyakarta. , 2006. Reliabilitas dan Validitas, Pustaka Pelajar, Yogyakarta.

Bangun, Wilson. 2012. Manajemen Sumber Daya Manusia, Erlangga, Jakarta.

Ghozali, Imam, 2001. Analisis Multivariate Dengan Program SPSS. Badan Penerbit Universitas Diponegoro, Semarang.

Handoko, T. Hani, 2011. Manajemen Personalia Dan Manajemen Sumber Daya Manusia. Edisi 2.

BPFE, Yogyakarta.

Hasan, Iqbal, 2006. Analisis Data Penelitian Dengan Statistik. Bumi Aksara, Jakarta.

Hasibuan, Malayu S.P., 2005. Manajemen Sumber Daya Manusia. PT. Bumi Aksara, Jakarta.

Mangkunegara, A.A. Anwar Prabu, 2005. Perilaku Dan Budaya Organisasi, Penerbit Refika

Aditama, Bandung. , 2011. Manajemen Sumber Daya Manusia, Penerbit

Rosdakarya, Bandung.

Martoyo, Susilo, 2000. Manajemen Sumber Daya Manusia, BPFE, Yogyakarta.

Munandar, Ashar Sunyoto, 2004. Psikologi Industri dan Organisasi. UI-Press, Jakarta.

Sugiyono, 2006. Metode Penelitian Bisnis. CV. Alfa Beta, Bandung.

Sukandarrumidi, 2006. Metodologi Penelitian. Gajah Mada University Press, Yogyakarta.

Tim Mitra Bestari, 2005. Manajemen Sumber Daya Manusia. Unit Penerbitan FE UMY, Yogyakarta. 